Review Article

\title{
A critical review on Rashtriya Arogya Nidhi scheme in India
}

\author{
Yuvaraj Krishnamoorthy*, Manikandanesan Sakthivel, Gokul Sarveswaran
}

\begin{abstract}
Department of Preventive and Social Medicine, Jawaharlal Institute of Postgraduate Medical Education and Research (JIPMER), Puducherry, India
\end{abstract}

Received: 15 February 2018

Revised: 10 March 2018

Accepted: 12 March 2018

\section{*Correspondence: \\ Dr. Yuvaraj Krishnamoorthy, E-mail: yuvi.1130@gmail.com}

Copyright: (c) the author(s), publisher and licensee Medip Academy. This is an open-access article distributed under the terms of the Creative Commons Attribution Non-Commercial License, which permits unrestricted non-commercial use, distribution, and reproduction in any medium, provided the original work is properly cited.

\begin{abstract}
Patients with life threatening diseases were not able to seek care in tertiary care settings in spite of availability of facilities because of the cost of care involved. This hampers the nation's progress towards Universal Health Coverage (UHC) by causing inequity in health service utilization and lack of financial protection to the families of the patient suffering from major diseases. Several government financial benefit schemes, both at central and state level, are available to cover the cost of care involved in the patients belonging to below poverty line (BPL) families. However, Rashtriya Arogya Nidhi is the only scheme which has been envisaged for providing comprehensive tertiary care benefit for patients with life threatening diseases belonging to BPL families. No government health programmes offers as much cash benefit as this scheme has been providing. This scheme, if utilized effectively can bring down the out-of-pocket expenditure considerably among the patients belonging to below poverty line families as well as increases the equity in utilization of tertiary care services. Even though the scheme was introduced two decades before, it has not been debated much for its utilization, impact, limitations and scopes for further improvement. Hence this review aims to critically appraise the strengths and limitations of the Rashtriya Arogya Nidhi scheme.
\end{abstract}

Keywords: Tertiary care, Rashtriya Arogya Nidhi, OOPE

\section{INTRODUCTION}

Health care delivery in India is going through a process of transition, more so the tertiary specialty care of chronic diseases like diabetes, hypertension, cardiac diseases, kidney or liver failure, mental illness and cancer. ${ }^{1}$ Patients, more commonly those from the lower economic strata, have difficulty in availing the health care services because of the costs involved in diagnostic and curative procedures. Even in public hospitals where the cost of care is low, patient had to bear several direct and indirect costs, commonly referred to as out-of-pocket expenditure (OOPE), which impoverish them further. As a result, patients with life threatening diseases requiring tertiary care often go untreated even if they are aware of the availability of high quality services. ${ }^{2}$ It can also lead to delay in diagnostic and curative procedures and even causing deaths of several thousands of poor patients. This issue has been a concern for nation's health policy, which should address the cost, quality and accessibility of health care. $^{1}$

One of the main goals of Universal Health Coverage (UHC) is to achieve equity in health service utilization. Even though inequity in service utilization is seen at all the levels of health care, tertiary care contributes to the maximum inequity because of the higher costs involved in the care. ${ }^{3}$ Even among those patients who utilize the services in view of life threatening diseases, OOPE is found to be high, leading to impoverishment. This is a clear deviation from the goal of providing financial protection to all families under UHC. ${ }^{1}$ Hence to achieve 
the UHC, a comprehensive scheme was required at the tertiary care level to reduce the economic burden of the families.

There are various government schemes under the health sector which provide financial assistance for below poverty line (BPL) families, both at central and state level. Central government funded schemes available are Prime Minister National Relief Fund (PMNRF), Rashtriya Swasthiya Bima Yojana (RSBY) and Rashtriya Arogya Nidhi (RAN). PMNRF provides financial assistance to indigent patients for the treatment of major diseases at designated hospitals through entirely public contribution. ${ }^{4}$ RSBY launched in 2008 , to reduce the outof-pocket expenditure and provide financial protection to below poverty line families, provides maximum benefit of only Rs. 30,000 per year per family. ${ }^{5}$ RAN launched in the year 1997 is the only scheme which comprehensively covers tertiary care cost for majority of the life threatening diseases among BPL patients. ${ }^{6}$

Despite the availability of these schemes for years, Outof-pocket expenditure (OOPE) is found to be consistently high. OOPE among the Indian population is found to be more than $60 \%$ as per the data from Household health expenditures in India 2013-14. ${ }^{7}$ More than one-third of these expenses are being spent on specialized curative care which involves intervention ranging from less complex procedures to highly sophisticated surgeries requiring the use of high end technology and skills. Hence we wanted to critically review the only scheme which provides comprehensive financial protection against the tertiary care cost, RAN, for its strengths and limitations.

\section{SITUATIONAL ANALYSIS}

Burden of major non-communicable diseases such as ischemic heart disease, cancer and neurological disorders which are to be dealt with tertiary care is found to be rising with poverty in countries like Bangladesh, China and India. ${ }^{8,9}$ Burden of cancer in India is increasing by approximately one million every year. More than half of these patients present at an earlier stage where curative procedures like chemotherapy, radiation therapy or surgery can be done and make the patients free from the disease. ${ }^{1}$ Patients requiring these curative procedures are in need of recurrent hospital admissions which might require higher cost of expenditure. In a survey done among major cities in India, it was found that more than one third of the cancer patients spent more than 50,000 rupees for total treatment as out-of-pocket expenditure. ${ }^{1}$

Cardiovascular disorders have now become the leading cause of mortality in India. Ischemic heart disease and stroke contributes to more than $80 \%$ of these deaths. Burden of cardiovascular diseases was initially found in people belonging to higher socio-economic status. However, transition of disease is happening towards the below poverty line people as well. Unfortunately, these patients cannot afford to spend on procedures and treatments for acute and severe cardiac conditions like Acute Coronary Syndrome (ACS) which might require thrombolysis, revascularization or any other evidence based treatments.

World Health Organization (WHO) published a document about the challenges in dealing with neurological disorders in the community. World Federation of Neurology also stressed about the importance of dealing with neurological disorders and the possible public health challenges in identifying and treating such disorders especially in the developing countries and resource constrained settings. ${ }^{10,11}$ The estimated burden of neurological disorders (excluding infections, traumatic injuries) of 30 million demands a public health approach, availability and accessibility of tertiary health care service. $^{12}$

Hence, in order to meet the need for tertiary care while providing financial security to people with low incomes, both Central and State Government have rolled out several social insurance and financial assistance programs that provide free tertiary care to patients from below poverty line families.

\section{EVOLUTION OF RASHTRIYA AROGYA NIDHI (RAN)}

Parliamentary standing committee on human resource development in their $31^{\text {st }}$ report on the functioning of Central Government Hospitals under Ministry of Health and Family Welfare raised concerns over the inadequate facilities available to treat major life threatening diseases for poor patients. They have stressed the importance of exploring all appropriate sources of funds to assist poor patients coming to Central Government Hospitals.

Based on these recommendations, government of India has set up national illness assistance fund which was later renamed as RAN in 1997 under the Department of Health and Family Welfare, Ministry of Health and Family Welfare. As per this scheme, cash assistance up to a maximum of 5 lakhs is provided to the patients who are belonging to below poverty line households and suffer from major life threatening diseases. It is applicable to the patients who receive treatment from any speciality or super specialty Government hospitals. This assistance will be provided as a "one time grant" to the Medical Superintendent/Director of the Institute in which the patient is getting treatment. This scheme, if implemented properly, is expected to help in early commencement of treatment and cut down the procedural delay for major life threatening conditions.

\section{ELIGIBILITY FOR ASSISTANCE}

Assistance is provided for those patients who belong to below poverty line status and suffer from any of the diseases specified in the list of life threatening conditions 
covered under the RAN scheme. However, this cash assistance scheme is applicable only for those patients who are getting admitted in the Government Hospitals. Government employees are not eligible to avail benefit from this scheme. Patients need to apply for this cash assistance before incurring any cost as they cannot reimburse the amount that is already spent.

\section{SETTING UP AND AVAILING OF FUNDS}

This scheme was started with capital investment of Rs. 5 crore from the Ministry of Health and Family Welfare (MoHFW). Major source of this fund is mainly from Ministry of Health and Family Welfare. However, contributions from the public, philanthropic organizations, corporate bodies in public and private sector are also utilized in funding this scheme. Currently, a revolving fund of 50 lakhs has been set up in 13 Central Government Hospitals throughout the country which might help in speeding up the cash assistance process. This fund is kept at the disposal of either Medical Superintendent or Director of the respective Institute. AIIMS has slightly higher financial power when compared to other central institutes as it receives a revolving fund of 90 lakhs per year. Financial powers to sanction the assistance amount are also delegated to Medical Superintendent or Director of the respective hospitals for patients satisfying the eligibility criteria. They can sanction assistance up to a maximum of 5 lakh rupees for emergency cases and 2 lakh rupees for other conditions covered under the scheme. The advance amount will be provided only after the utilization report is received from the respective institute. Apart from this, state illness assistance fund has also been set up in all Indian States and Union Territories except Nagaland and Meghalaya.

For the States/UTs where illness fund has been set up, Grant in aid from Central Government will be released based on the proportion of below poverty line population. For States with large number of below poverty line population, maximum of 5 crore will be released while 2 crores will be released for other States/UTs. From this fund, maximum of 1.5 lakh can be spent for each patient. If the patient's expenditure exceeds this amount, then such patient needs to be referred to RAN Headquarters in New Delhi for further financial assistance.

Fund can be availed by the patient by submitting an application enclosed with medical report from the treating doctor or head of the department in which the patient is getting treated, original monthly income certificate, copy of ration card attested by a gazetted officer.

\section{HEALTH MINISTER'S CANCER PATIENT FUND (HMCPF)}

This scheme was set up within RAN in the year 2009 to offer cash assistance to cancer patients belonging to below poverty line. Funding for this scheme is mainly through the capital investment of Rs. 100 crore which has been set up as a fixed deposit. Interest generated from this fund is being utilized to grant the cash assistance.

Revolving Fund up to a maximum of 50 lakhs has been set up in 27 Regional Cancer Centres (RCC). Financial power is vested with Medical Superintendent or Director of the respective Institutes. Maximum benefit of Rs. 2 lakh can be provided for each case and the patients requiring assistance exceeding this limit will be referred to headquarters of MoHFW for further assistance. Eligibility criteria are similar to the RAN scheme.

\section{HEALTH MINISTER'S DISCRETIONARY GRANT (HMDG)}

Another scheme was launched under RAN in the year 2013 to provide partial financial assistance for expenditure incurred in the treatment of life threatening diseases in Government Hospitals. This scheme was extended to the people with annual family income up to 1 lakh. No other centrally sponsored financial assistance scheme covered families with annual income more than 1 lakh. This scheme provides cash assistance up to a maximum of Rs. 1.25 lakh based on the estimated cost required for the treatment.

\section{UTILISATION OF FUNDS}

Annual report of RAN 2015-16 reported that Rs. 14.76 crore has been released for the treatment of 376 patients. For State Illness Assistance Fund, Rs. 11.75 crore has been released in total in the year 2015-16. For the HMCPF scheme, Rs. 979 lakhs has been released to the RCCs and totally 260 patients have availed the fund in the financial year 2015-16. For HMDG scheme, Rs. 219 lakhs has been released and totally 280 patients have been benefitted under this scheme in the year 2015-16.

\section{CRITICAL APPRAISAL}

RAN scheme, if properly implemented and utilized, has several strengths vested in it. One of the major strength of the scheme is the reduction in financial burden of the patients from BPL families with life threatening diseases. This is the only scheme which provides maximum financial assistance up to 5 lakhs to patients with major diseases admitted to Government speciality/super speciality hospitals. Availability of revolving fund at hospital level and state level helps to cut down the procedural delay and earlier initiation of curative procedures.

The two separate schemes introduced under RAN scheme in the past decade, besides helping to speed up the assistance process for cancer patients, also extend the benefit to family with annual income up to 1 lakh. This extension of benefit is supposedly another added advantage of the scheme compared to other financial 
assistance schemes in India, until the newly proposed National Health Protection Scheme (Union Budget 201718 ) is implemented.

This scheme can help to reduce the gap between the need and actual use of health service at tertiary level for major diseases and also protects individuals and households from the financial ruin or adverse effects on their economic livelihood which in turn help to achieve Universal Health Coverage (UHC) at tertiary care level in India.

In spite of these strengths, this scheme has its own limitations. Under-utilization of the fund is one of the major weaknesses of this scheme. Burden of the major diseases like cardiac, neurological and cancer were found to be significantly high in India. But less than 1000 patients have availed benefit through all the three schemes under RAN as per the annual report for the financial year 2015-16. This can be due to poor publicity of the national scheme and lack of awareness among the BPL families. Another disadvantage of the scheme is the lack of separate indicators or committee for monitoring and evaluation, without which it will be difficult to find out the relevance, effectiveness, efficiency and impact of activities in the light of specific objectives of the scheme.

This scheme can be availed for the patients who are admitted in Government speciality/super speciality hospitals only. However, majority of the Indian population seek speciality diagnostic and curative services from private health care facilities. Hence, exclusion of private hospitals from the scheme cannot effectively reduce the out-of-pocket expenditure among the patients with major diseases.

\section{Recommendations}

Surveys need to be conducted throughout the India to check the knowledge of BPL families regarding this scheme. Awareness campaigns can be conducted to increase the utilization of this scheme throughout the country. Setting up of separate committee for monitoring and evaluation of the scheme can be done. Development of new indicators can help to check the effectiveness and impact of the scheme.

Upscaling of facilities for the treatment of life threatening diseases in public tertiary care hospitals can be done without compromising quality and accessibility. This will enable more number of patients to avail services from public facilities and hence will be eligible for availing the scheme. Enhancing public-private partnership i.e. inclusion of private hospitals under the scheme can be helpful to the patients who are seeking private health facilities until the capacity of public facilities to handle more number of patients are improved.

\section{CONCLUSION}

RAN is a major financial assistance scheme which can have significant impact on the economic livelihood of patients from below poverty line with major diseases. However, the scale of utilization of the fund needs to be increased in order to achieve equity in health care utilization and provide financial protection to all the families in the country with patients having life threatening diseases. This scheme, if implemented effectively, can help to progress towards Universal Health Coverage at the tertiary care level.

Funding: No funding sources

Conflict of interest: None declared

Ethical approval: Not required

\section{REFERENCES}

1. Mohanti BD, Mukhopadhyay A, Das S, Sharma K, Dash S. Estimating the economic burden of cancer at a tertiary public hospital: a study at the All India Institute of Medical Sciences. Indian Statistical Institute, New Delhi, India; 2011.

2. Whitehead M, Dahlgren G, Evans T. Equity and health sector reforms: can low-income countries escape the medical poverty trap? Lancet. 2001;358:833-6.

3. The world health report 2010. Health systems financing: the path to universal coverage. Geneva, World Health Organization, 2010.

4. PM India. PM National Relief Fund, 2017. Available at http://www.pmindia.gov.in/en/pmsfunds/. Accessed on 16 February 2018.

5. Ministry of Labour and Employment. Government of India; New Delhi: 2008. RSBY Guidelines. MoLE. Available at: http://www.rsby.gov.in/ Documents.aspx?id=25/. Accessed on 16 February 2018.

6. Ministry of Health and Family Welfare. Rashtriya Arogya Nidhi. MoHFW. Available at https://mohfw.gov.in/poorpatientsfinancialassistan/r ashtriya-arogya-nidhi. Accessed on 16 February 2018.

7. Ministry of Health and Family Welfare. Household health expenditures in India (2013-14). MoHFW. Available at: https://mohfw.gov.in/sites/default/ files/38300411751489562625. Accessed on 16 February 2018.

8. Yusuf S, Reddy S, Ônpuu S, Anand S. Global burden of cardiovascular diseases. Part II: Variations in cardiovascular disease by specific ethnic groups and geographic regions and prevention strategies. Circulation 2001;104:285564.

9. Ferlay J, Shin H-R, Bray F, Forman D, Mathers C, Parkin DM. Estimates of worldwide burden of cancer in 2008: GLOBOCAN 2008. Int J Cancer. 2010;127:2893-917. 
10. World Health Organisation. Neurological disorders, Public health challenges. Geneva: World Health Organisation; 2006: 218.

11. World Health Organisation, World Federation of Neurology. Atlas. Country resources for neurological disorders. Geneva: World Health Organisation; 2004: 59.

12. Gourie-Devi M. Epidemiology of neurological disorders in India: Review of background, prevalence and incidence of epilepsy, stroke,
Parkinson's disease and tremors. Neurol India. 2014;62:588-98.

Cite this article as: Yuvaraj K, Manikanda Nesan S, Gokul S. A critical review on Rashtriya Arogya Nidhi scheme in India. Int J Community Med Public Health 2018;5:1239-43. 